\title{
Algorithm for Public Electric Transport Schedule Control for Intelligent Embedded Devices
}

\author{
Ivars Alps, Riga Technical University, Andrey Potapov, Riga Technical University, \\ Mikhail Gorobetz, Riga Technical University, Anatoly Levchenkov, Riga Technical University
}

\begin{abstract}
In this paper authors present heuristics algorithm for precise schedule fulfilment in city traffic conditions taking in account traffic lights. The algorithm is proposed for programmable controller. PLC is proposed to be installed in electric vehicle to control its motion speed and signals of traffic lights. Algorithm is tested using real controller connected to virtual devices and real functional models of real tram devices. Results of experiments show high precision of public transport schedule fulfilment using proposed algorithm.
\end{abstract}

Keywords: public electric transport, algorithm for intelligent controller, traffic lights control

\section{INTRODUCTION}

Nowadays in cities number of vehicles is increasing day by day. Traffic jams are the main reason for a lot of problems for public transport like delays, inefficient usage of energy etc. Fulfilment of the schedule in such conditions is unforeseen. And service level of public transport is going down.

Therefore some solutions to fulfil the schedule are necessary. There are some different ways to reach the goal.

The first possible solution is to change to schedule of the transport on-the-fly and show new schedule on the electronic tables of the passenger stops [1]

Another solution is to improve service level is to increase number of electric transport units. But this solution increases expenses of public transport companies in times [6].

In previous papers authors proposed two solutions such as optimal speed and schedule control [2] and "green wave" [4], which allows the tram to switch the traffic light to green for the time that is necessary to cross the road. The tram is moving from one passenger stop to another without any additional braking on the traffic lights.

In this paper new improved algorithm of uninterrupted motion of public electric transport and schedule completion is proposed and adopted to for industrial controller to create coordinated traffic lights working to public electric transport's good and to fulfil the schedule to provide better service.

\section{PROBLEM FORMULATION}

To organize uninterrupted moving on the route is very important for standby time decreasing and consider the schedule in public transport. Currently in the Riga city traffic lights and public transport units are working separate from each other. They have not shared control system and have not coordinated along public transport routes.

If transport units moving on the route and traffic lights will work coordinated, this could decrease electric transport standby time, eliminate often breaking and acceleration, finally save electricity.

The purpose of this research is to create algorithm for electric transport moving control on the route according predefined schedule to put into practice the controller. Object of research is public electric transport system.

Main tasks of research are the following:

- to define structure of public electric transport with intelligent controllers;

- to develop algorithm of schedule fulfilment of public electric transport for programmable controller;

- to create computer model of proposed embedded control system;

- to create a functional model with real and virtual devices with realization of control algorithm in PLC.

Electric transport control system consists of vehicle moving control scheme, programmable controller and DC drive model as shown in Fig.1. Electric transport units receive GPS signal about current location, controller according received signal and predefined schedule calculate and send through transmitters signal for DC drive control and in same time relevant signal to traffic lights.

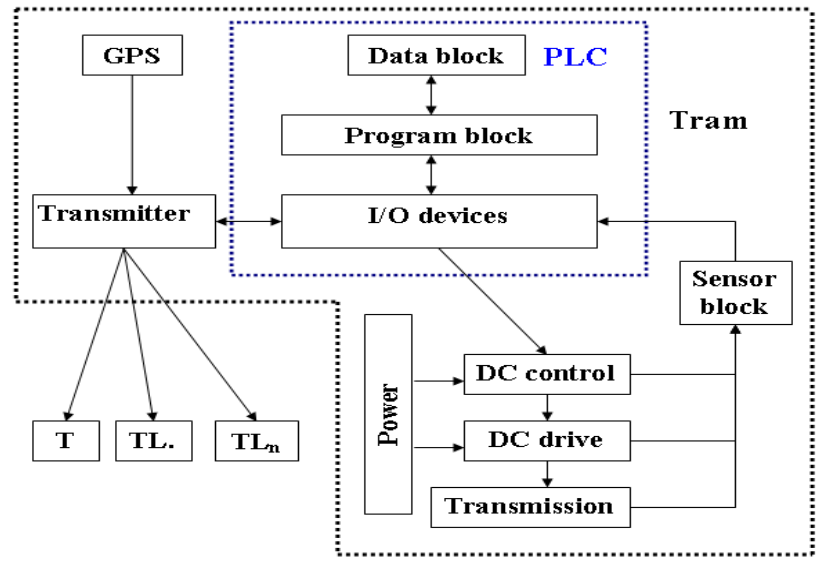

Fig. 1. Structure of control system of electric transport and traffic lights.

Pulse width adjustment technique for DC drives is proposed. PLC changes the pulse width depending on the received signals and pre-set data. As a result is DC drives rotational speed changes. Limit to the maximum rotational speed of $20 \mathrm{~m} / \mathrm{s}$ is given for this task. Mechanical load during simulation is constant. Electrical scheme for DC drives with PLC control is presented in Fig.2. 


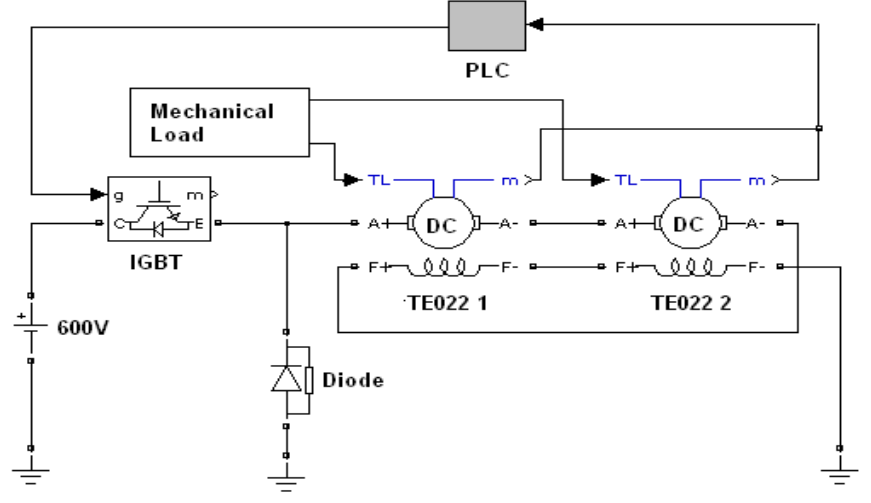

Fig. 2. Electrical scheme for DC drives control.

The following input data are necessary for the controller of the tram:

- Coordinates of passenger stops

- Coordinates of traffic lights

- Tram arrival time for passenger stops

- Tram waiting time on stops

Motion controller of the tram continuously receives data about the current transport spatial position and current time. The required speed for electric vehicle is calculated in accordance to the distance to the next stop.

Optimal time point to switch a next traffic light signal to green is calculated depending on the instant location and time. It provides a continuous movement of vehicles without stopping.

\section{MATHEMATICAL MODEL FOR ALGORITHM}

\section{A. Nomenclature}

Following definitions are proposed for mathematical model of algorithm:

1) A set of processors $P$ - stops and traffic lights, where $P=$ $\{\mathrm{P} 1, \mathrm{P} 2\}, \mathrm{P} \in \mathrm{N}$ while Stops:

$$
P^{1}=\left\{p_{1}^{1}, p_{2}^{1}, \ldots, p_{s}^{1}\right\} \subset P
$$

Traffic lights:

$$
P^{2}=\left\{p_{1}^{2}, p_{2}^{2}, \ldots, p_{c}^{2}\right\} \subset P
$$

2) A set of jobs $T$ - vehicles, where $T=\{=t 1, t 2, \ldots, t \mathrm{tm}\}$ Each vehicle has the schedule:

$\forall t \in T, \quad \sigma_{u}: P^{1} \rightarrow\left\{t_{u 1}, t_{u 2}, \ldots, t_{u s}\right\} \subset \mathfrak{R}$

Each passenger stop has the schedule:

$\forall p \in P^{1}, \quad \sigma_{p}: T \rightarrow\left\{t_{p 1}, t_{p 2}, \ldots, t_{p m}\right\} \subset \mathfrak{R}$

\section{B. Parameters for DC drive}

Each vehicle U DC drive $\mathrm{E}$ has following electrical and mechanical parameters:

$\mathrm{I}_{\mathrm{ie}}-$ field current;

$\mathrm{I}_{\mathrm{e}}$ - armature current;

$\mathrm{c}_{\mathrm{f}}$ - magnetic flux;

$\mathrm{c}_{\mathrm{m}}=\mathrm{cf} / 2 \pi-$ rotation torque constant;

$\mathrm{n}$ - rotation speed (apgr./s);

$\omega-$ rotation speed $(\mathrm{rad} / \mathrm{s})$;

$\mathrm{U}_{\mathrm{m}}$ - DC engine voltage

$\mathrm{L}_{\mathrm{e}}$ - armature inductance

$\mathrm{R}_{\mathrm{e}}$ - armature resistance

$\mathrm{L}_{\mathrm{ie}}-$ field inductance

$\mathrm{R}_{\mathrm{ie}}$ - field resistance

$\mathrm{L}_{\text {eie }}$ - field-armature mutual inductance

$\mathrm{g}$ - duty ratio of pulse regulation

$\mathrm{E}_{\mathrm{v}}$ - used vagon energy

$\mathrm{J}$ - inertia

$\mathrm{B}_{\mathrm{m}}-$ viscous friction coefficient

$\mathrm{T}_{\mathrm{L}}-$ torque

$\mathrm{T}_{\mathrm{ie}}-$ Coulomb friction torque

In this investigation the centre of attention is $\omega$ - rotation speed $(\mathrm{rad} / \mathrm{s})$;Following parameters of the electric transport vehicle are controlled and calculated:

$\mathrm{V}_{\mathrm{T}}$ - vehicle speed

$\mathrm{S}_{\mathrm{T}}$ - vehicle made by way

$\mathrm{t}_{\text {current }}$ - current time

$\mathrm{S}_{\mathrm{TP}}$ - distance between vehicle and object

$\mathrm{S}_{\mathrm{br}}-$ stopping distance

$\mathrm{t}_{\mathrm{br}}$ - required braking time

$\mathrm{V}_{\text {req }}$ - required vehicle speed

$t_{\text {stop }}$ - vehicle motion time till next stop

$\mathrm{t}_{\mathrm{t}}-$ vehicle motion time till next traffic light

\section{Formulas that will be used in the calculation algorithm:} $\mathrm{V}_{\mathrm{T}}$ tram speed $(\mathrm{km} / \mathrm{h})$ :

$$
V_{T}=\frac{\omega \cdot 2 \pi \cdot R}{R_{p}}
$$

where

$$
\begin{array}{ll}
- & \mathrm{R} \text { - tram wheel radius }(\mathrm{m}) ; \\
- & \mathrm{R}_{\mathrm{p}} \text { - reduction gear ratio } \mathrm{R}_{\mathrm{p}}=7,36 \text {. }
\end{array}
$$

Tram braking distance $(\mathrm{m})$ :

$$
S_{b r}=\frac{V_{T}^{2}}{2 \cdot a}
$$

The distance between current position of the tram $X_{T}$ and the position of the stop $X_{P}(m)$ :

$$
S_{T P}=X_{P}-X_{T}
$$


Braking time (s):

$$
t_{b r}=\frac{V_{T}}{a}
$$

Time to stop the motion at constant speed $\mathrm{V}_{\mathrm{T}}(\mathrm{s})$ :

$$
t_{\text {motion }}=\frac{S_{T P}}{V_{T}}
$$

Braking distance and the distance to the stop the comparison:

$$
S_{b r} \leq S_{T P}
$$

The remaining travel time to the next stop $t_{\text {rem }}(s)$ :

$$
t_{\text {rem }}=t_{P}-t_{\text {current }}
$$

Required speed $\mathrm{V}_{\text {required }}(\mathrm{m} / \mathrm{s})$ :

$$
V_{\text {required }}=\frac{S_{T P}}{t_{\text {rem }}}
$$

Formulas for obtaining the required parameters of the tram

Engine speed $\omega\left(\mathrm{min}^{-1}\right)$ :

$$
\omega=(g-40) \cdot 70
$$

Simplified the calculation it is assumed that at $40 \%$ pulse width of the engine speed is already equal to zero, but at $100 \%$ of the voltage pulse width speed is $4200 \mathrm{~min}-1$.

Tram speed $\mathrm{V}_{\mathrm{T}}(\mathrm{m} / \mathrm{s})$ :

$$
V_{T m s}=V_{T k m / h} \cdot k
$$

where $\mathrm{k}$ - the calculated ratio $k=0,27777$

\section{ALGORITHM FOR INTELLIGENT CONTROLLER FOR TASK SOLUTION}

The public electric transport system object location scheme that will be used in the calculation algorithm is presented in Fig.3

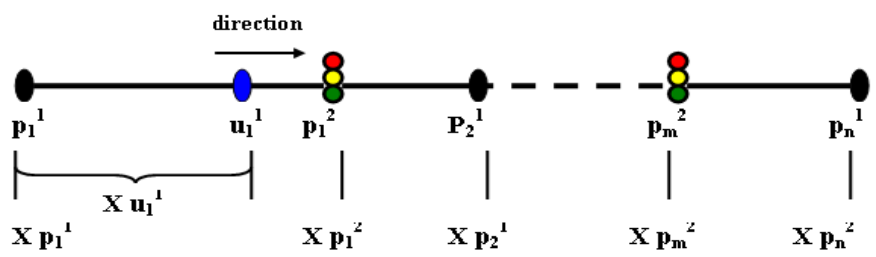

Fig. 3. The public electric transport system object location scheme.
The steps of algorithm are described below:

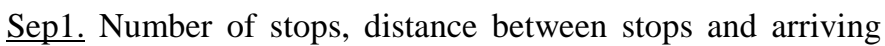
times are defined:

Stops $\mathrm{Xp}=\{1,2, \ldots \mathrm{n}\}$

Traffic lights $\mathrm{X} 1=\{1,2, \ldots \mathrm{m}\}$

Speed increasing Const $_{\mathrm{V}}$

Time increasing Const $t_{t}$

Start point location: $S_{\text {curr }}$

Start time: $\mathrm{t}_{\text {curr }}$

Tram arriving time cchedule in stops:

$t_{p}=\{2,3, \ldots n\}$

Step2. START ; Start simulation

Step3. GET $S_{\text {curr }}$; Get tram current location, equal to distance between starting point and tram current lication

Step4. GET $\mathrm{t}_{\text {curr }}$; Get current time

Step5. $\mathrm{V}_{\text {curr }}=\mathrm{S}_{\text {curr }} / \mathrm{t}_{\text {curr }} ;$ Calculate tram current velocity

Step6. $S_{\text {rem }}=X_{\text {pnext }}-S_{\text {curr }}$; Calculate remaining distance up to next stop

Step7. $\mathrm{t}_{\text {req }}=\mathrm{S}_{\mathrm{rem}} / \mathrm{V}_{\text {curr }} ;$ Calculate requesting time to go remaining distance up to next stop

Step8. IF $\mathrm{t}_{\text {req }}+\mathrm{t}_{\text {curr }}<\mathrm{t}_{\text {pnext }}$; Compare requesting time to go and schedule provided arrived time in next stop

\section{YES}

$\underline{\text { Step9. }} \mathrm{V}_{\text {curr }}+$ Const $_{\mathrm{V}} ; \mathrm{t}_{\text {curr }}+$ Const $_{\mathrm{t}}$; Increase current time and speed

Go to Step3.

NO

Step10. $S_{\text {br(req) }}=V_{\text {curr }} \wedge 2 / 3.6$; Calculate tram required braking distance up to next speed with current speed

Step11. IF $\mathrm{S}_{\mathrm{br}(\mathrm{req})}>\mathrm{X}_{\text {pnext }}-\mathrm{S}_{\mathrm{curr}}$; Compare tram required braking distance with distance between tram and next stop YES

$\underline{\text { Step12. }} \mathrm{V}_{\text {curr }}-$ Const $_{\mathrm{v}} ; \mathrm{t}_{\text {curr }}+$ Const $_{\mathrm{t}} ;$ Decrease current speed and increase current time

Go to Sep3.

NO

Step13. $\mathrm{S}_{\text {rem(lnext) }}=\mathrm{Xl}_{\text {next }}-\mathrm{S}_{\text {curr }}$; Calculate remaining distance up to next traffic light

Step14. $\mathrm{t}_{\text {req(Inext) }}=\mathrm{S}_{\text {rem(Inext) }} / \mathrm{V}_{\text {curr }} ;$ Calculate requesting time to go from current location up to next traffic light

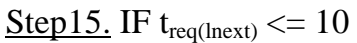

YES

Step16. Set Signal R+Y

NO

Go to Step3.

Step17. IF t $\mathrm{t}_{\text {req(lnext) }}<=4$;

YES

Step18. Set Signal G

NO

Go to Step3.

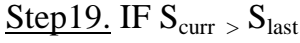

YES

Step20. END

NO

Go to Step3.

Program block diagram is presented in Fig.4-5. 
1. SET $\{\mathrm{xp}, \mathrm{X} 1, \mathrm{t}\}$, Consty. Const $\mathrm{S}_{\mathrm{gux}}, \mathrm{t}_{\mathrm{coux}}$

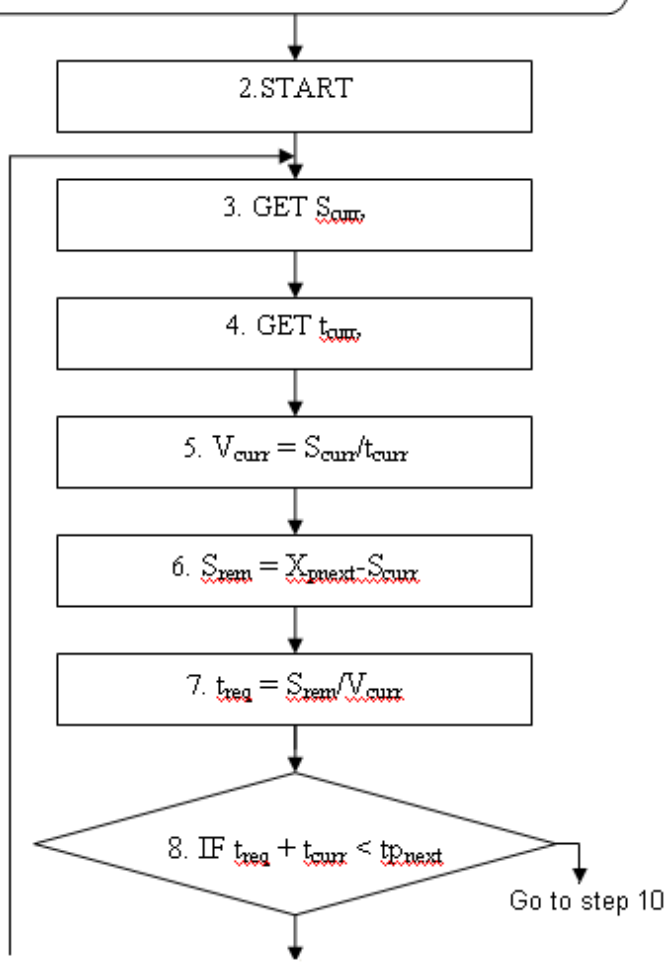

Fig. 4. Algorithm block diagram.

\section{COMPUTER EXPERIMENT IN DEVELOPING OF INTELLIGENT CONTROLLER ALGORITHM}

A part of public electric transport route was chosen as an example for computer experiment. It consists of four stops and three traffic lights. For algorithm programming industrial controller SIEMENS SIMATIC S7-200 was used.

Corresponding distance between stops and arriving in stops schedule is shown in tab. 1 .

TABLE 1.

STOPS LOCATION AND ARRIVING SCHEDULE

\begin{tabular}{|r|r|r|r|r|}
\cline { 2 - 5 } \multicolumn{1}{c|}{} & Stop 0 & Stop 1 & Stop 2 & Stop 3 \\
\hline Distance (m) & 0 & 1000 & 1900 & 3200 \\
\hline Arr. time (s) & 0 & 100 & 200 & 350 \\
\hline
\end{tabular}

Corresponding distance between start and traffic lights is shown in tab.2.

TABLE 2.

TRAFFIC LIGHTS LOCATION

\begin{tabular}{|c|c|c|c|}
\cline { 2 - 4 } \multicolumn{1}{c|}{} & Traff.light 1 & Traff.light 2 & Traff.light 3 \\
\hline Distance $(m)$ & 600 & 1500 & 2700 \\
\hline
\end{tabular}

From step 8

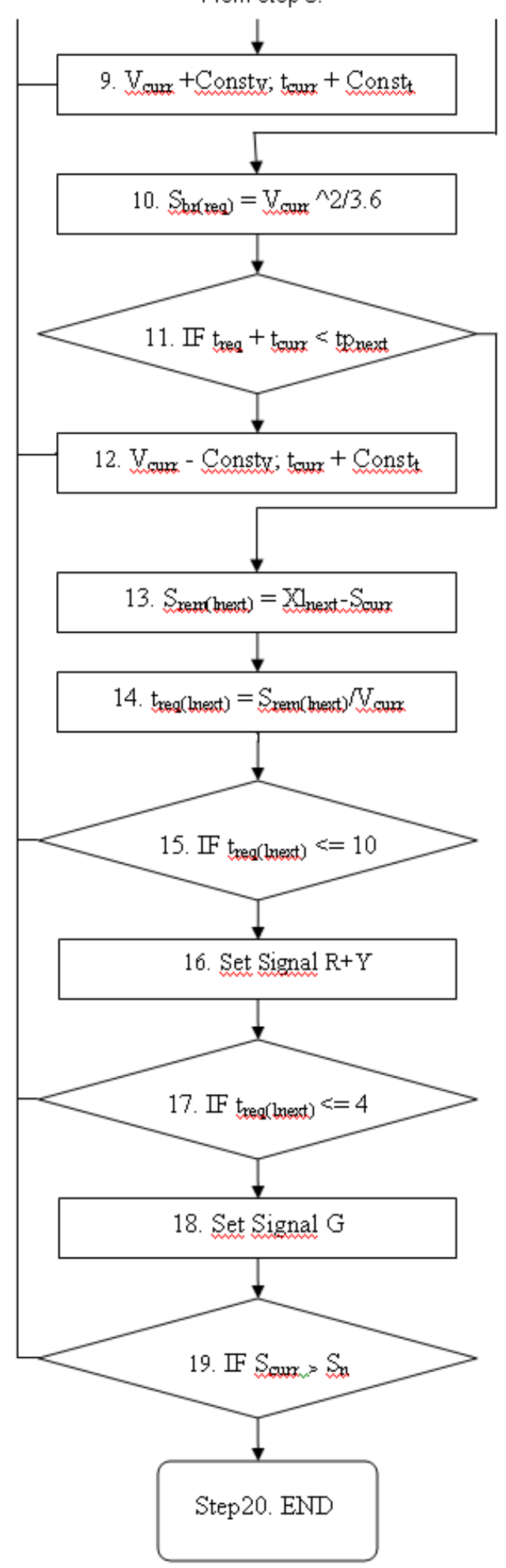

Fig. 5. Algorithm block diagram (continuation).

Basic data was entered in SIEMENS SIMATIC S7-200 computer program Step7-Micro/Win. Part of programming code in Step7-Micro/Win environment is present in Fig.6. 
Network 1

Get distance up to $\mathrm{P} 1$, time to go up to $\mathrm{P} 1$, requesting velocity to go up to P1 and calculate requesting velocity

ID SMO.O

MOVR \#XP:LD0, AttIiidzP1: VD116

AENO
$-\mathrm{R}$

AENO
AR<

MOVR

AENO

MOVR

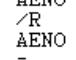

\begin{tabular}{|l|l|l|}
\hline Symbol & Address & Comment \\
\hline AttLiidzP1 & VD116 & Distance up to Stop1 $(\mathrm{m})$ \\
\hline Snobraukt & VD38 & Tram way to go $(\mathrm{m})$ \\
\hline TbrliidzP1 & VD150 & Time to go up to Stop1 (s) \\
\hline Vtnepiec & VD144 & Tram requesting velocity $[\mathrm{m} / \mathrm{s})$ \\
\hline
\end{tabular}

Network 2

\begin{tabular}{|c|c|c|}
\hline \multicolumn{3}{|c|}{\begin{tabular}{|l|} 
Braking distance \\
\end{tabular}} \\
\hline \multirow{4}{*}{$\begin{array}{l}\text { LD } \\
\text { MOVR } \\
\text { AENO } \\
\text { /R } \\
\text { AENO } \\
\mathrm{R} \\
\text { AENO } \\
\text { MOVR } \\
* \mathrm{R}\end{array}$} & \multicolumn{2}{|c|}{$\begin{array}{l}\text { SM0.0 } \\
\text { Vtms:VD26, Brlaiks:VD136 }\end{array}$} \\
\hline & \multicolumn{2}{|c|}{ 1.8, Brlaiks: VD136 } \\
\hline & \multicolumn{2}{|c|}{ 2.0, Brlaiks: VD136 } \\
\hline & \multicolumn{2}{|c|}{$\begin{array}{l}\text { Vtms: VD26, Brceljsh: VD132 } \\
\text { Brlaiks:VD136, Brceljsh:VD132 }\end{array}$} \\
\hline Symbol & Address & Comment \\
\hline Brcelish & VD132 & Braking distance (m) \\
\hline Brlaiks & VD136 & Braking time [s] \\
\hline Vtms & VD26 & Velocity $[\mathrm{m} / \mathrm{s})$ \\
\hline
\end{tabular}

Network 3

\begin{tabular}{|c|c|c|}
\hline \multirow{6}{*}{$\begin{array}{l} \\
\text { ID } \\
\text { MOVR } \\
\text { AENO } \\
-\mathrm{R} \\
\text { AENO } \\
\text { MOVR } \\
\text { AEENO } \\
\text { R } \\
\text { AENO } \\
\text { AR }> \\
\text { AR } \\
\text { AR }\end{array}$} & \multirow{2}{*}{\multicolumn{2}{|c|}{$\begin{array}{l}\text { SM0:0 } \\
\text { \#XI: LD8, AttIiidzL1: VD128 }\end{array}$}} \\
\hline & & \\
\hline & \multicolumn{2}{|c|}{ Snobraukt: WD38, AttIiidzL1: WD128 } \\
\hline & \multicolumn{2}{|c|}{ AttIiidzL1: VD128, TbrIiidzP3: VD158 } \\
\hline & \multicolumn{2}{|c|}{ Vtms:VD26, TbrLiidzP3:VD158 } \\
\hline & \multicolumn{2}{|c|}{$\begin{array}{l}\text { TbrIiidzP3: VD158, } 9.0 \\
\text { TbrLiidzP3:VD158, } 9.5 \\
\text { M5.4 }\end{array}$} \\
\hline Symbol & Address & Comment \\
\hline AttLiidzL1 & VD128 & Distance up to Traffic light1 (m) \\
\hline Snobraukt & VD38 & Tram way to go (m) \\
\hline TbrLliidzP33 & VD158 & Time to go up to Stop3 (m) \\
\hline Vtms & VD26 & Velocity $[\mathrm{m} / \mathrm{s}]$ \\
\hline
\end{tabular}

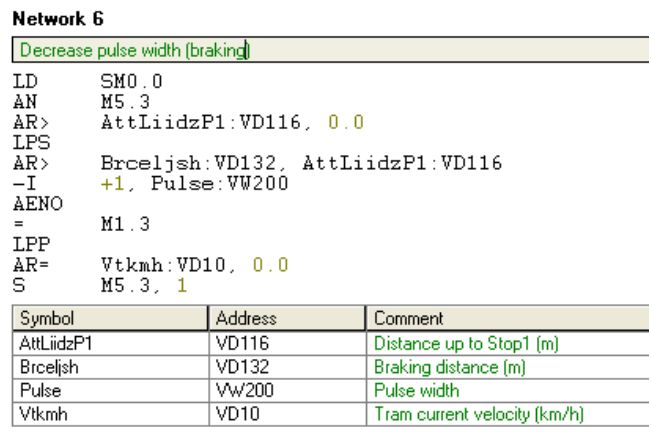

Network 9

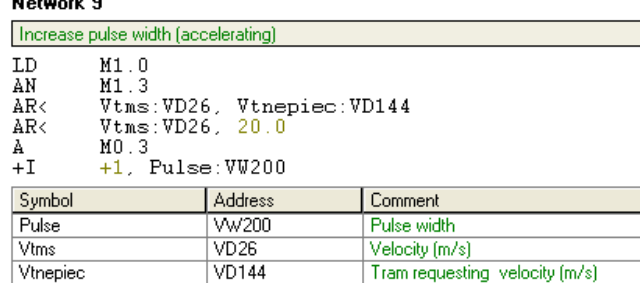

Fig. 6. Part of programming code in Step7-Micro/Win environment.
GREEN light duration

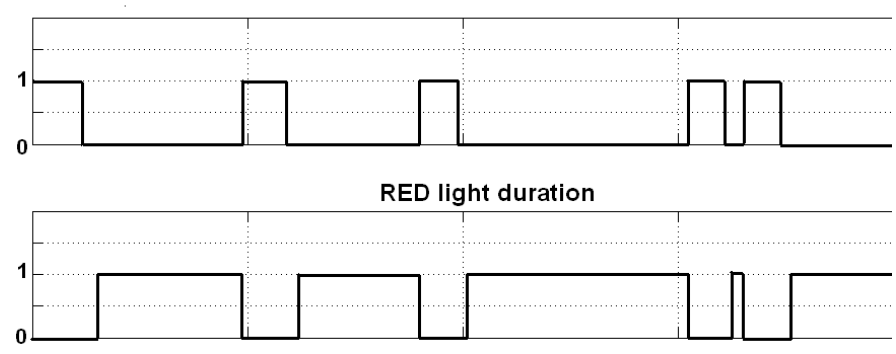

Distance
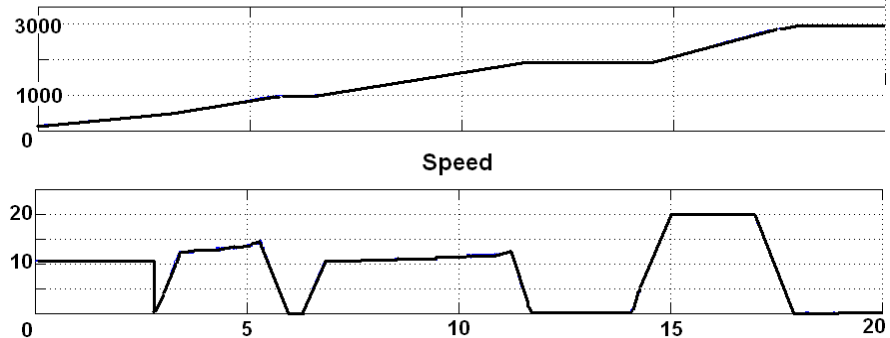

Fig. 7. Tram completed distance, speed on route and traffic lights operating modes.

This part of program show calculation of several parameters: Network 1. Required speed dependent of distance up to next stop

Network 2. Required braking distance up to full stop

Network 3. Required braking distance up to full stop at the current speed depending on the current location

Network 6. Braking simulation i.e. decrease pulse width depending on the distance up to next stop, required braking distance and tram current speed

Network 9. Acceleration simulation i.e. increase pulse width depending on tram current and required speed

The tram motion and to approach to traffic light was simulated and result of computer experiment was read in computer program Matlab Simulink environment. Tram completed distance, speed on route and traffic lights operating modes are shown in Fig.7.

\section{CONCLUSIONS}

To analyzed in computer program Matlab Simulink fixed diagrams the conclusions are:

- traffic light mode RED and GREEN are switched corresponds the tram location on the route and task conditions about distance from vehicle up to next traffic light;

- the tram motion speed is control entire whole route with purpose consider predefined schedule;

- algorithm for intelligent controller can be used to solve public electric transport flow organization tasks ;

- industrial controller can be used for intelligent public electric transport schedule control. 
Using the "green wave" method is given the privileges for electric transport comparing to others; cars, trucks, pedestrians, etc. Advantages are:

- the uninterrupted motion of electric transport units decrease amount of braking-accelerating cycle on the route and therefore decrease total electric energy consumption;

- as less is electric energy consumption as cheaper passenger traffic could be provided;

- interrupted motion of electric transport units gives opportunity for optimal speed control and for considering predefined schedule.

On the other hand privilege for one type of vehicle traffic could bring about inconvenient for other types of vehicles and pedestrians. Proposed method possible imperfections are:

- staying time on crossroads for other types of vehicles is increased

- increased staying time on crossroads could step up volume and dimension of traffic jam.

To define saving up electricity and project influence on possible traffic jams it is necessary to implement additional researches.

\section{REFERENCES}

[1] L.Ribickis, M.Gorobetz, A.Levchenkov. Intelligent Electric Vehicle Motion And Crossroad Control. //In Proceedings of 12th International Power Electronics and Motion Control Conference. Portoroz, Slovenia, $2006-1239-1244 \mathrm{p}$.

[2] I. Rankis, M. Gorobetz, A. Levchenkov. Optimal Electric Vehicle Speed Control By Intelligent Devices. Rīgas Tehniskās universitātes raksti. Enerǵētika un Elektrotehnika. Sērija 4, sējums 16. 2006. 127-137. lpp.
[3] Kuei-Hsiang Chao, Ren-Hao Lee, Meng-Hui Wang. An Intelligent Traffic Light Control Based on Extension Neural Network// Department of Electrical Engineering, National Chin-Yi University of Technology, Taichung, Taiwan, R.O.C. Lecture Notes in Computer Science, Springer Berlin / Heidelberg, Germany, 2008

[4] M. Gorobetz, A. Levchenkov. Evolutionary Algorithms and Dynamic Parameters for Public Electric Transport Modelling //In Proceedings of 16th Mediterranean Conference on Control and Automation, Ajaccio, France, 25-27 June 2008, 215-219p

[5] Wiering, M. A. Multi-agent reinforcement learning for traffic light control. In Langley.// In Proceedings of the Seventeenth International Conference on Machine Learning (ICML'2000), Stanford University, June 29 to July 2 2000, USA, pages $1151-1158$.

[6] Marco Wiering, Jelle van Veenen, Jilles Vreeken, Arne Koopman. Intelligent Traffic Light Control. Institute of Information and Computing Sciences, Utrecht University. Padualaan 14, The Netherlands, 2004

[7] Marek Horyński. Intelligent Electric Systems in Urban Traffic Control. Department of Computer and Electrical Engineering, Lublin University of Technology, TEKA Kom. Mot. Energ. Roln. - OL PAN, Poland, 2007

Ivars Alps. He is a doctoral student of Institute of Industrial Electronics and Electrical Engineering at Riga Technical University since 2008. He got engineer diploma in mechanical engineering and machine building in 1986, M.sc.ing. degree in 2008. Main fields of scientific interests are neural networks, artificial immune algorithm, scheduling theory, intelligent electric transport systems. He has several publications in proceedings of international conferences.

Andrey Potapov. He is a bachelor student of Institute of Industrial Electronics and Electrical Engineering at Riga Technical University since 2006. Main fields of scientific interests are programming of embedded intelligent devices in intelligent electric transport.

Anatoly Levchenkov. He is professor of Institute of Industrial Electronics and Electrical Engineering at Riga Technical University since 2006. He got engineer diploma in electrical engineering in 1969, Dr.sc.ing. degree in 1978. His fields of interests are optimization theory, group decision support systems, negotiation support systems, scheduling, intelligent logistics transport systems. He was head of project in Development of multiagent systems for Latvian Council of Science, head of project in Development of program for decision support for Latvian Maritime Company and other projects.

Mikhail Gorobetz. He is graduated Doctor of Science at Riga Technical University Institute of Industrial Electronics and Electrical Engineering in 2008. Fields of scientific interests are electronic intelligent agents, negotiations, bond graphing, neural networks, clustering, genetic algorithms. Main results are published in area of energy saving, safety control, mechatronics, dynamic modeling and simulation. He participates in Latvian Council of Science projects. 